\title{
Journal of Thermal Spray Technology Volume 21 Best Paper Awards
}

It is with great pleasure that the Journal of Thermal Spray Technology (JTST) announces the winners of the JTST Volume 21 Best Papers Awards, as chosen by an international committee of expert judges. The awards were presented at the International Thermal Spray Conference \& Exposition 2013, in Busan, Republic of Korea.

"Three-Dimensional Simulation of Porosity in Plasma-Sprayed Alumina Using Microtomography and Electrochemical Impedance Spectrometry for Finite Element Modeling of Properties" by Olivier Amsellem, Francois Borit, Dominique Jeulin, Vincent Guipont, Michel Jeandin, Elodie Boller, and Frederic Pauchet won JTST Volume 21 Best Paper. The Honorable Mention went to "Engineering the Microstructure of Solution Precursor Plasma-Sprayed Coatings" by Gabriele Bertolissi, Christophe Chazelas, Giovanni Bolelli, Luca Lusvarghi, Michel Vardelle, and Armelle Vardelle.

The Editorial Committee believes it is important to evaluate the quality of engineering and scientific contributions published in JTST and to provide recognition of excellent work and its publication. Each paper is reviewed and evaluated on its merits for scientific and engineering content, originality, and presentation style. The following papers are recognized as outstanding and the authors received awards of recognition for their excellent publications.

The international committee of judges led by Dr. Roland Seals, Chair of the Journal of Thermal Spray Technology Best Paper Subcommittee, is as follows: Arvind Agarwal, David Bucci, Andrew Gouldstone, Jan Ilvasky, George Kim, Keehyun Kim, Anand Kulkarni, Jiri Matejicek, Timothy McKechnie, Shiladitya Paul, James Ruud, Richard Schmid, Igor Sevostianov, Atin Sharma, Philip Shipway, Yoshiki Tsunekawa, Erja Turunen, Anirudha Vaidya, Alfredo Valarezo, Joel Voyer, Petri Vuoristo, and Makoto Watanabe.

Congratulations are extended to the winning authors from the JTST Editorial Board and the ASM Thermal Spray Society Executive Board of Directors.

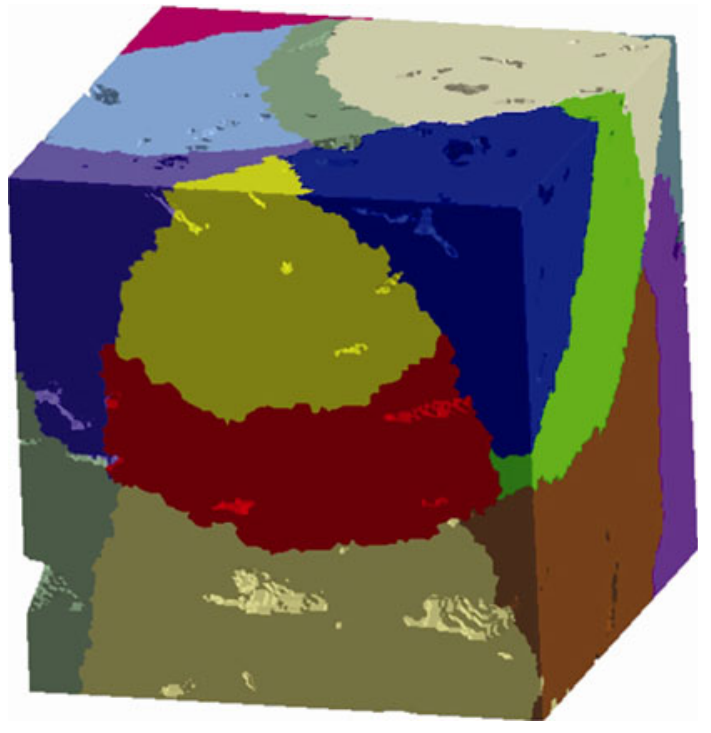

Sub-domains from 3D meshing built with triangulated surface models from the JTST Best Paper "Three-Dimensional Simulation of Porosity in Plasma-Sprayed Alumina Using Microtomography and Electrochemical Impedance Spectrometry for Finite Element Modeling of Properties."

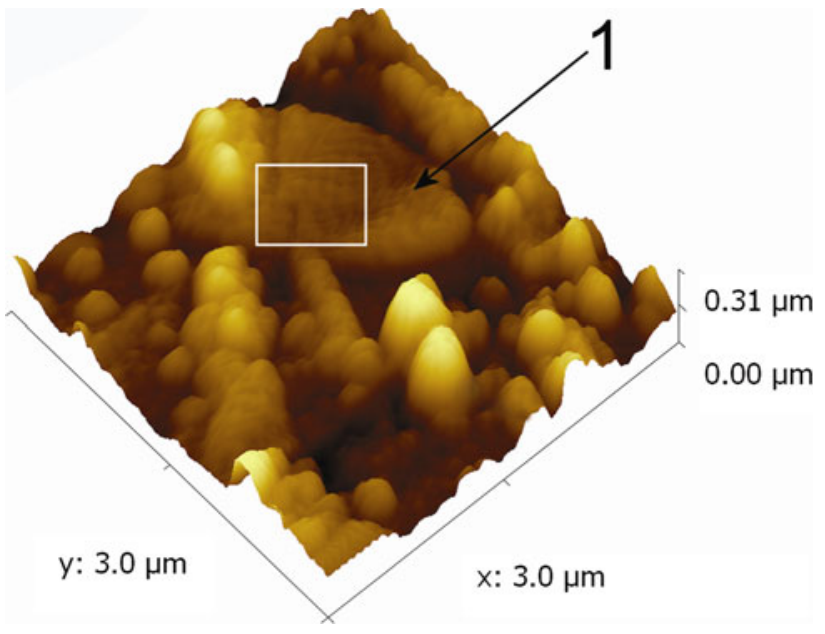

AFM image of cubic- $\mathrm{ZrO}_{2}$ coating with extremely smooth splat surface (1) unlike those of conventional plasma sprayed ceramic splats from "Engineering the Microstructure of Solution Precursor Plasma-Sprayed Coatings." 